\title{
RISK FACTORS OF NEUROLOGCAL LESIONS IN LOW CERMCAL SPINE FRACTURES AND DISLOCATIONS
}

\author{
DANILOGONÇALVES COELHO*, ALBERT V. B. BRASIL**, NELSON PIRES FERREIRA***
}

\begin{abstract}
Eighty-nine patients with lower cervical spine fractures or dislocations were evaluated for risk factors of neurological lesion. The age, sex, level and pattern of fracture and sagittal diameter of the spinal canal were analysed. There were no significant differences on the age, gender, level and Torg's ratio between intact patients and those with nerve root injury, incomplete or complete spinal cord injuries. Bilateral facet dislocations and burst fractures are a significant risk factor of spinal cord injury.
\end{abstract}

KEY WORDS: cervical spine, fractures, dislocations, spinal cord injury.

Fatores de risco de lesão neurológica nas fraturas e luxações da coluna cervical baixa

RESUMO - O risco de lesão neurológica foi avaliado em 89 pacientes com fraturas ou luxações da coluna cervical baixa. Foram analisados o sexo, a idade, o diâmetro sagital do canal vertebral, o nível e o tipo de fratura ou luxação. Não foram encontradas diferenças significativas para a idade, sexo, nível da fratura ou luxação e razão de Torg entre os pacientes intactos e aqueles com lesão radicular, lesão medular incompleta e lesão medular completa. Luxações bilaterais de facetas articulares e fraturas em explosão são um fator de risco significativo de lesão neurológica.

PALAVRAS-CHAVE: coluna cervical, fratura, luxação, lesão medular.

The pattern and the intensity of neurological injury that occurs during lower cervical spine fractures and dislocations have been correlated to many factors. Examples of these factors are the amount of spinal cord disruption ${ }^{1,2}$, and the fracture characteristics and degree of displacement ${ }^{1,3-8}$. The relationship between the degree of displacement and the degree of neurological injury is not unanimously accepted ${ }^{9,10}$.

Spinal cord injuries without osteoligamentous injury and severe fracture and dislocations in neurologically intact patients are sometimes seen in daily practice ${ }^{11,12}$. The size of the spinal canal (before the traumatic event) has been naturally interpreted as one of the explanations for this discrepancy, but there is no general agreement in this point ${ }^{11-18}$.

In order to identify risk factors for neurological injury, the records of 89 patients who had sustained lower cervical spine trauma were retrospectively reviewed in our institution.

\section{METHOD}

The records of all patients older than 18 years admitted to Hospital São José da Santa Casa de Misericórdia de Porto Alegre (HSJ), between 1980 and 1995, with the diagnosis of trauma to the lower cervical spine (C3-C7)

Hospital São José da Irmandade da Santa Casa de Misericórdia de Porto Alegre: *MD, M. Sc. Orthopaedic Surgeon; **MD, Ph.D., Neurosurgeon; MD, Chief Neurosurgeon, Professor of Faculdade de Medicina da Universidade Federal do Rio Grande do Sul and Fundação Faculdade Federal de Ciências Médicas de Porto Alegre. Aceite: 1-agosto-2000.

Dr. Danilo Gonçalves Coelho - Rua Guilherme Alves 1602 - 90680-000 Porto Alegre RS - Brasil. 


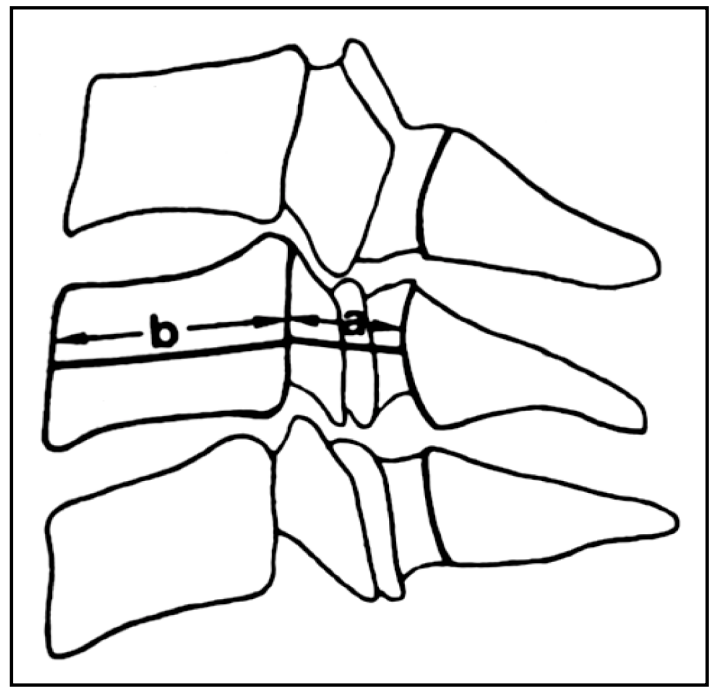

Fig 1. The Torg's ratio $(a / b)$ is a comparison between the sagittal diameter of the spinal canal (a) and the sagittal diameter of the vertebral body $(b)$.

were reviewed. In order to build a uniform group, patients with the following characteristics were excluded: spinal cord injury without fracture or dislocation, previous surgery and congenital or acquired spinal deformities or diseases (with the exception of spondylosis).

The patients were divided into four groups according to the pattern of neurological injury: 1- no neurological injury, 2- radicular symptoms, 3- incomplete spinal cord injuries, 4- complete spinal cord injuries. They were further classified according to the pattern of bone and ligament lesion as follows: unilateral facet fracture or dislocation, bilateral facet dislocation, burst fracture and miscellaneous lesions. The spinal canal sagittal diameter was measured using the Torg's ratio ${ }^{19}$. The Torg's ratio is a comparison between the sagittal diameter of the spinal canal and the sagittal diameter of the vertebral body on the lateral radiograph of the cervical spine (Fig 1). The mean Torg's ratio for each patient was calculated. Whenever some level could not be calculated, the contiguous levels' mean was used. The value from C6 was used for C7.

The sex, level and pattern of osteoligamentous lesion were analysed by chi-square. The age and sagittal diameter were submitted to analysis of variance. The odds ratio (OR) for complete spinal cord lesion was evaluated among patients harbouring unilateral facet fracture or dislocation, burst fracture and bilateral facet dislocation.

Patients without spinal cord injury (Groups 1 and 2) and patients with spinal cord involvement (Groups 3 and 4) were grouped separately to allow logistic regression. The significance level chosen for all statistical analysis was $\mathrm{p}<0,05$.

\section{RESULTS}

One hundred thirty four patients were admitted to HSJ during the period of the study. Forty five cases were excluded for the following reasons: congenital cervical spine deformity - 1 patient; ankylosing spondylitis - 1 patient; previous laminectomy - 2 patients; spinal cord injury without fracture or dislocation - 18 patients; inadequate radiological records - 23 patients. The remaining eighty-nine cases constituted the material for this study.

Twenty-four patients had no neurological injury (Group 1), and thirteen had radicular symptoms (Group 2). A spinal cord injury was found in 52 patients: 31 incomplete (Group 3) and 21 complete (Group 4). The mean age was $36.8 \pm 13.2$ years (mean \pm standard deviation) for all patients. The mean age varied in the different groups: Group 1- $38.25 \pm 14.86$; Group 2- $36.69 \pm 12.41$; Group 3$35.96 \pm 12.79$ and Group $4-36.61 \pm 13.1$. The analysis of variance showed that the difference in age 


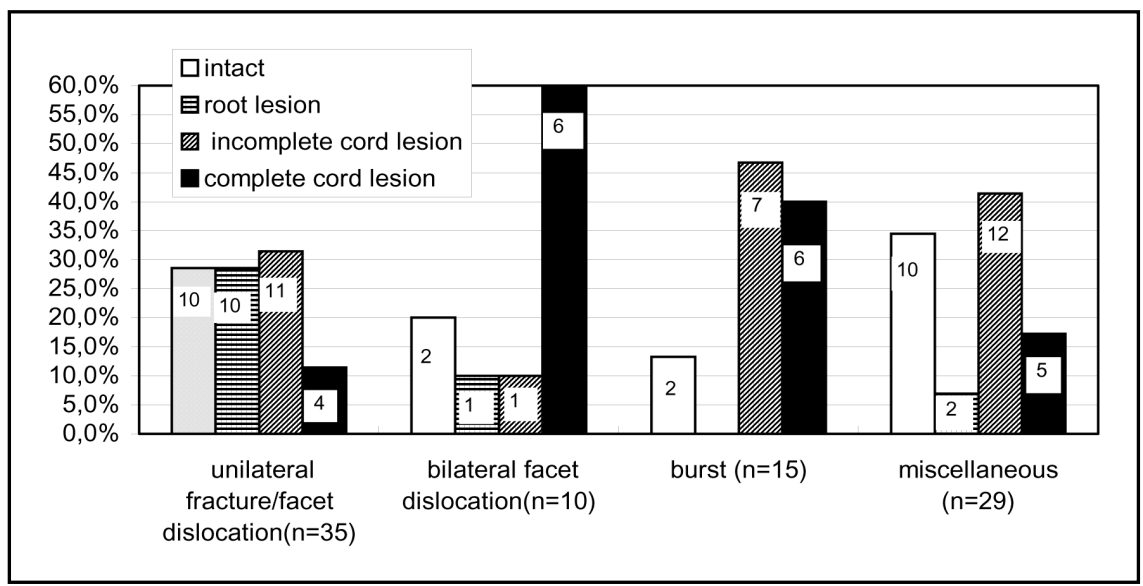

Fig 2. Distribution of neurological syndrome by pattern of bone and ligament injury.

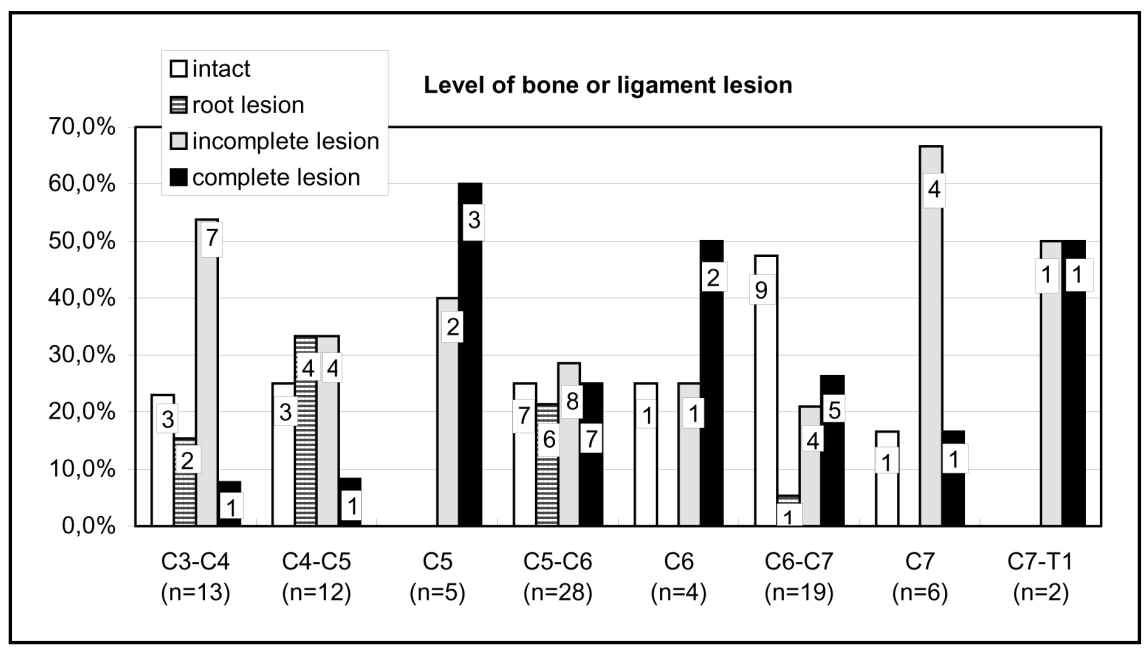

Fig 3. Level of injury distribution.

was not significant $(\mathrm{p}=0.939)$. The male/female ratio was $72 / 17$ for the whole group. This ratio was $17 / 7$ in Group 1, 9/4 in Group 2, 28/3 in Group 3 and 18/3 in Group 4. Chi-square showed that the differences observed were not significant $(\mathrm{p}=0.186)$.

The bone and ligament injuries were $35(39.32 \%)$ unilateral facet fractures or dislocations, 10 (11.23\%) bilateral facet dislocations, 15 (16.58\%) burst fractures and 29 (32.58\%) miscellaneous. The distribution of neurological syndromes according to the patterns of bone and ligament injury (Fig 2) was analysed by the chi-square and disclosed a significant difference between the groups $(\mathrm{p}=0.006)$. The OR for complete spinal cord lesion was evaluated among patients harbouring unilateral facet fracture or dislocation, burst fracture and bilateral facet dislocation (miscellaneous lesions were eliminated from this analysis). The OR of a complete spinal cord injury for burst fractures was 5.2 with a $95 \%$ confidence interval of $0.98-29.05(\mathrm{p}=0.048)$; and 11.6 for bilateral facet dislocations with a $95 \%$ confidence interval of $1.79-87.37(\mathrm{p}=0.004)$.

The relation between neurological syndrome and the level of bone and ligamentous lesion is presented in Figure 3. Chi-square disclosed no statistically significant difference $(p=0.261)$. 
Table 1. Logistic regression results.

\begin{tabular}{lccc}
\hline & $\mathrm{p}$ & OR & CI 95\% \\
\hline $\begin{array}{l}\text { Mean Torg's ratio } \\
\quad 1,02\end{array}$ & 0,7416 & 1,00 & - \\
$0,92-1,01$ & 0,9855 & 1,01 & $(0,26-3,99)$ \\
$0,82-0,91$ & 0,5006 & 1,60 & $(0,41-6,25)$ \\
$\quad<0,82$ & 0,3808 & 1,91 & $(0,45-8,16)$ \\
Bone and ligament lesion's pattern & & & \\
$\quad$ unilateral facet fracture or dislocation & 0,0452 & 1,00 & - \\
$\quad$ burst fracture & 0,1691 & 3,22 & $(0,61-17,0)$ \\
$\quad$ bilateral facet dislocation & 0,0075 & 11,36 & $(1,91-67,52)$ \\
$\quad$ miscellaneous & 0,2773 & 1,83 & $(0,62-5,41)$ \\
Gender & & & \\
$\quad$ female & 0,0876 & 0,34 & $(0,10-1,17)$ \\
$\quad$ Age & & & \\
$\quad \leq 28$ & 0,6859 & 1,00 & - \\
$28-32$ & 0,7626 & 1,26 & $(0,29-5,52)$ \\
$33-45$ & 0,2884 & 2,10 & $(0,53-8,31)$ \\
$\geq 46$ & 0,8817 & 1,11 & $(0,27-4,64)$ \\
constant & 0,3846 & - & - \\
\hline
\end{tabular}

The mean Torg's ratio in Group 1 was: $0.9254 \pm 0.1327$, in Group 2: $0.9459 \pm 0.1139$, in Group 3: $0.9226 \pm 0.1197$ and in Group 4: $0.8976 \pm 0.1045$. Analysis of variance showed no significant difference $(\mathrm{p}=0.261)$.

Logistic regression (Table 1), was made by grouping together patients from Groups 1 and 2 (no neurological deficit and radicular symptoms) and from Groups 3 and 4 (incomplete and complete spinal cord injury). This analysis demonstrated that bilateral facet dislocation is a strong risk factor for spinal cord injury $(\mathrm{OR}=11.36[\mathrm{p}=0.0075])$. Age was not a significant risk factor for spinal cord injury. The Torg's ratio showed a trend towards an increased risk of spinal cord injury for patients with smaller values. This trend, however, was not statistically significant.

\section{DISCUSSION}

The chance of a neurological lesion to occur during a cervical spine fracture or dislocation depends on many factors. Probably, the most important of these factors is the degree of energy absorbed by the spine. Unfortunately, this variable cannot be directly measured. Some indirect estimates of this amount of energy are thus utilised for this purpose - the degree of spinal displacement and spinal cord deformity, for example. Our results demonstrate that the OR of spinal cord injury in bilateral facet dislocation, which is a lesion with greater amount of vertebral displacement and spinal cord deformity, is 11.36 and in burst fractures it is 3.22 , when compared to unilateral facet dislocation, for logistic regression. The value for burst fractures is not significant $(p=0.169)$, but for bilateral dislocation the value is highly significant $(\mathrm{p}=0.0075)$. The OR of complete spinal cord injury, using univariate analysis, was 5,2 for burst fractures $(\mathrm{p}=0,048)$ and 11,6 for bilateral facet dislocations $(\mathrm{p}=0,004)$. The present findings are in accordance with those from other authors ${ }^{1,5-7,16}$.

Age and sex were not demonstrated to constitute risk factors for neurological injury in the present series.

In 1984, Eismont ${ }^{14}$ found an inverse relationship between the sagittal diameter of the spinal canal and the occurrence of spinal cord injury during trauma. The findings from Matsuura et al. ${ }^{17}$, 
Kang et al. ${ }^{16}$ and Barros et al. ${ }^{13}$ corroborate Eismont's opinion. The findings from Lintner et al. ${ }^{4}$ in a group of patients with unilateral facet dislocations, and those from Torg et al..$^{18}$ in football players, suggest that this correlation does not exist. Our results showed a trend towards a greater risk of spinal cord injury in patients with a Torg's ratio below $0.82(\mathrm{OR}=1.91[\mathrm{p}=0.3808])$. We suppose this difference would be significant in case our series comprised a larger amount of cases.

\section{Conclusions}

Data from the present material suggest that bilateral facet dislocations and burst fractures have a greater risk of spinal cord lesion in lower cervical spine trauma, when compared to unilateral facet dislocations and other types of osteoligamentous lesions.

Acknowledgements - We are in debt with Dr. Mario B. Wagner for his help with the statistical analysis of this paper.

\section{REFERENCES}

1. Bohlman HH. Acute fractures and dislocations of the cervical spine: an analysis of three hundred hospitalized patients and review of the literature. J Bone Joint Surg 1979;61A:1119-1142.

2. Ladd AL, Scranton PE. Congenital cervical stenosis presenting as transient quadriplegia in athletes. J Bone Joint Surg 1986;68A:1371-1374.

3. Chang DG, Tencer AF, Ching RP, Senft D, Anderson PA. Geometric changes in the cervical spinal canal during impact. Spine 1994;19:973-980.

4. Lintner DM, Knight RQ, Cullen JP. The neurological sequelae of spinal facet injuries-The role of the canal diameter. Spine 1993; 18:752-759.

5. Marar BC. The pattern of neurological damage as an aid to the diagnosis of the mechanism in cervical spine injuries. J Bone Joint Surg 1974;56A:1648-1654.

6. Norton WL. Fractures and dislocations of the cervical spine. J Bone Joint Surg 1962;44A:115-139.

7. O'Brien PJ, Schweigel JF, Thompson WJ. Dislocations of the lower cervical spine. J Trauma 1982;22:710-714.

8. Raynor RB, Koplik B. Cervical cord trauma: the relationship between clinical syndromes and force of injury. Spine 1985;10:193-197.

9. Barnes R. Paraplegia in cervical spine injuries. J Bone Joint Surg 1948;30B:234-244.

10. Edwards WC, La Rocca H. The developmental sagittal diameter of the cervical spinal canal in patients with cervical spondylosis. Spine 1983;9:20-27.

11. Dayes LA, Boyd W, Peterson D, Ritland S. The fortune of a capacious canal. J Nat Med Assoc 1979;71:985-987.

12. Pitman MI., Pitman CA, Greenberg IM. Complete dislocation of the cervical spine without neurological deficit: a case report. J Bone Joint Surg 1977;59A:134-135.

13. Barros TE P Filho, Oliveira RP, Cunha MRR, Kalil EM, França AF. Avaliação do canal vertebral nos traumatismos da coluna cervical. Acta Ortop Bras 1995;3:59-61.

14. Eismont FJ, Clifford S, Goldberg M, Green B. Cervical spinal canal size in spine injury. Spine 1984;9:663-666.

15. Ersmark H, Löwenhielm P. Factors influencing the outcome of cervical spinal injuries. J Trauma 1988;28:407-410.

16. Kang JD, Figgie MP, Bohlman HH. Sagittal measurements of the cervical spine in subaxial fractures and dislocations. J Bone Joint Surg 1994;76A:1617-1628.

17. Matsuura P, Waters RL, Adkins RH, Rothman S, Gurbani N, Sie I. Comparison of computerized tomography parameters of the cervical spine in normal control subjects and spinal cord-injured patients. J Bone Joint Surg 1989;71A:183-188.

18. Torg JS, Naranja RJ Jr, Pavlov H, Galinat BJ, Warren R, Stine RA. The relationship of developmental narrowing of the cervical spinal canal to reversible and irreversible injury of the cervical spinal cord in football players. J Bone Joint Surg 1996;78A:1308-1314.

19. Torg JS, Pavlov H, Genuario SE et al. Neurapraxia of the cervical spinal cord with transient quadriplegia. J Bone Joint Surg 1986;68A:1354-1370. 